Por um populismo de esquerda.

MOUFFE, Chantal. For a Left Populism. London/Verso, 2018.

Revista Ensaios, vol. 15, jul-dez de 2019.

\title{
Por um Populismo de Esquerda
}

Michele Diana Luz ${ }^{1}$

MOUFFE, Chantal. For a Left Populism. London/Verso, 2018.

O populismo é um conceito cujo emprego sempre implica em críticas. Em voga novamente devido às múltiplas experiências contemporâneas identificadas como expressões suas, o termo tem vivido um novo momentum, tanto à esquerda quanto à direita, dentro e fora da academia.

Em "For a left Populism” (Por um Populismo de Esquerda) a teórica política Chantal Mouffe apresenta o que denomina como "uma proposta de intervenção política". Deixando claro que o livro não tem a pretensão de servir como resolução teórica acerca do populismo - apesar de esta intenção perpassar subliminarmente a narrativa da obra - a autora opta pelo princípio maquiaveliano de situar sua reflexão na conjuntura que analisa, a qual circunscreve-se à realidade dos países da Europa Ocidental. Tal delimitação é justificada pelo entendimento de que os países do Leste europeu e da América Latina, assim como suas respectivas culturas políticas, requerem uma análise peculiar, a qual se abstém de fazer nesta ocasião.

O argumento central da autora é apresentado com clareza logo no início da obra: para interferir na crise de hegemonia, é necessário que se estabeleça uma nova fronteira política e que o populismo de esquerda, entendido como uma estratégia discursiva de

\footnotetext{
${ }^{1}$ Graduada em Ciências Sociais pela Universidade Federal de Pelotas (UFPeL). Mestre em Ciência Política (2017) pela Universidade Federal de Pelotas (UFPeL). Doutoranda em Ciência Política pelo Instituto de Filosofia, Sociologia e Política da Universidade Federal de Pelotas (IFISP/UFPel) com período sanduíche junto ao Centre for Applied Philosophy, Politics and Ethics (CAPPE), da University of Brighton. Brasil, Pelotas, Rio Grande do Sul. micheledluz@gmail.com.
} 
Por um populismo de esquerda.

MOUFFE, Chantal. For a Left Populism. London/Verso, 2018.

Revista Ensaios, vol. 15, jul-dez de 2019.

construção de fronteiras políticas entre "o povo" e a "oligarquia" constitua, na presente conjuntura, o tipo de política necessária para recuperar e aprofundar a democracia (Mouffe, 2018, p. 4). O que isso implica em termos empíricos, no entanto, é mais adequadamente desdobrado no decorrer do livro.

De antemão, é importante esclarecer que a formulação de populismo adotada é a de Ernesto Laclau, cujas bases restam na formulação da teoria do discurso ${ }^{2}$ feita por Laclau e Mouffe anos antes e aprimorada por Laclau em sua Obra "A razão populista". Assim sendo, o populismo é entendido como uma estratégia discursiva de construção de uma fronteira dividindo a sociedade em dois campos e a mobilização dos desfavorecidos contra aqueles no poder (Laclau, 2005). Não se trata de uma ideologia e, portanto, não pode ser atribuída um conteúdo programático específico. Tampouco é um regime político. É uma forma de fazer política que pode assumir vários formatos ideológicos, de acordo com o lugar e o tempo, sendo igualmente compatível com uma variedade de enquadramentos institucionais.

Dito isto, a premissa inicial da qual Mouffe parte em "O momento populista" é a afirmação de que o cenário atual nas democracias europeias é o de um "momento populista", decorrente da crise da hegemonia liberal, cujo primeiro abalo sério se mostrou na crise financeira de 2008. Alegando que a crise em questão não restringe-se ao domínio econômico, mas concerne a toda uma concepção de sociedade cujos limites começaram a ser, a partir de então, mais claramente expostos, a autora assevera que a visível incapacidade das instituições existentes em assegurar sua aliança com o povo revelou-se sintomática em vários casos, quando estas, ao serem confrontadas, optaram por dar prioridade à ordem existente.

Para Mouffe, a falta de solução para esta crise é justamente o que caracteriza o momento populista, cujo cerne reside na expressão de uma variedade de resistências às transformações políticas e socioeconômicas vivenciadas durante os anos de hegemonia

\footnotetext{
${ }^{2}$ Hegemony and Socialist Strategy (1985).
} 
Por um populismo de esquerda.

MOUFFE, Chantal. For a Left Populism. London/Verso, 2018.

Revista Ensaios, vol. 15, jul-dez de 2019.

do neoliberalismo (demandas insatisfeitas). Em sua visão, essas transformações levaram à uma situação de pós-democracia, por ela entendida como a erosão dos dois pilares de uma democracia ideal: igualdade e soberania popular. Aprofundando este argumento, a autora esclarece que quando falamos de democracia na Europa, estamos falando de um modelo específico, que é um regime político caracterizado pela articulação de duas tradições diferentes: por um lado, a tradição do liberalismo político, que apresenta a democracia como o império da lei, da defesa da liberdade e respaldada na separação dos poderes; por outro, a tradição democrática circunscrita às ideias de igualdade e soberania popular.

O entendimento de pós-democracia de Mouffe propõe avançar nas conceituações apresentadas por Colin Crouch $^{3}$ e Jacques Rancière ${ }^{4}$ ao inserir uma nova faceta do neoliberalismo. Conforme argumenta, o que caracteriza a pós-democracia é o fato de que, nos anos recentes, a tensão agonística entre os princípios liberais e democráticos (constitutivos da democracia) foram eliminados, de modo que a democracia foi reduzida ao seu componente liberal, significando apenas a presença de eleições livres e a defesa de direitos humanos. As eleições não mais oferecem aos cidadãos a oportunidade de uma decisão real através dos partidos, de modo que a única escolha possível é entre partidos de centro-direita e centro-esquerda. Assim, a política se tornou um mero instrumento de gerenciamento da ordem vigente, fazendo da soberania popular obsoleta.

Mouffe retoma o conceito de pós-política ${ }^{5}$, que diz respeito à diluição das fronteiras políticas entre direita e esquerda, para reforçar que a submissão dos partidos social-democratas às sanções do capital financeiro eliminou a possibilidade de uma luta entre diferentes projetos de sociedade - condição para o exercício da soberania popular assim como a defesa da igualdade do discurso liberal-democrático.

${ }^{3}$ Colin Crouch, Post-Democracy (Cambridge, 2004).

${ }^{4}$ Jacques Rancière, Disagreement: Politics and Philosophy (University of Minnesota Press, 1999).

${ }^{5}$ Chantal Mouffe, On the Political (Abingdon, UK: Routledge, 2005). 
Por um populismo de esquerda.

MOUFFE, Chantal. For a Left Populism. London/Verso, 2018.

Revista Ensaios, vol. 15, jul-dez de 2019.

Para além disso, estes partidos demonstraram também a incapacidade de entender o momento populista e encarar o desafio que ele representa por estarem presos aos seus dogmas pós-políticos e relutantes em admitir seus erros, o que impede que reconheçam que muitas das demandas articuladas pelos partidos populistas de direita são demandas democráticas, para as quais uma resposta progressista deve ser dada, especialmente por virem de grupos que foram os principais afetados pela globalização neoliberal.

Como a experiência europeia mostrou, inicialmente, a maior parte das resistências contra o consenso veio da direita, que foi capaz de traduzir as demandas de setores populares que se sentiam excluídos do consumo dominante em uma linguagem nacionalista e criando uma bem-sucedida fronteira entre o povo versus o establishment político. No entanto, esse panorama mudou em 2011, quando manifestações antiglobalização e anti-austeridade, como os "movimentos das praças", tomaram este espaço, sendo interpretados como sinais de despertar político após anos de relativa apatia.

Para Mouffe, o que está em jogo no seio do momento populista é como as resistências da pós-democracia serão articuladas e como o povo será construído, o que em sua visão não requer uma quebra revolucionária com o regime liberal-democrático. $\mathrm{O}$ que deve estar em pauta é uma estratégia adequada para estancar a emergência dos partidos populistas de direita em sua cooptação do sentimento de abandono e desejo por reconhecimento democrático dos eleitores.

Usando a experiência do Thatcherismo como exemplo, a autora sustenta que a ação decisiva deve ser o estabelecimento de uma fronteira que quebre com o consenso pós-político entre a centro-direita e a centro-esquerda. Sem definir um adversário, nenhuma ofensiva hegemônica é possível de ser lançada, o que implica desafiar a visão de democracia como consenso e restaurar os valores democráticos da igualdade e da soberania popular. Seu otimismo ampara-se na percepção de que essa intervenção é possível porque esses valores democráticos seguem tendo um papel significativo no

${ }^{6}$ Ganharam maior destaque os Movimentos 12M (Portugal) e o $15 \mathrm{M}$ ou Indignados (Espanha). 
Por um populismo de esquerda.

MOUFFE, Chantal. For a Left Populism. London/Verso, 2018.

Revista Ensaios, vol. 15, jul-dez de 2019.

imaginário político de nossas sociedades, nas quais o significante democracia estabelece conexão com valores políticos centrais às aspirações populares. Por isso, uma estratégia populista de esquerda deve estar inscrita na tradição democrática, porém, seu sentido deve ser reativado para subverter a ordem hegemônica e criar uma ordem diferente.

Mouffe vê na construção de um "povo" e de uma "vontade coletiva" que resultem da mobilização de afetos comuns na defesa da igualdade e da justiça social a possibilidade de combate às políticas xenófobas promovidas pelo populismo de direita. Nesse sentido, seu argumento é de que, para barrar a ascensão do populismo de partidos de extrema direita, faz-se necessária uma resposta política adequada, que deve vir através de um movimento populista de esquerda que una todas as demandas democráticas contra a pósdemocracia. Para tanto, é preciso ter em mente que, ao invés de excluir a priori os eleitores de partidos populistas de extrema direita e vê-los como motivados por paixões atávicas - condenando-os, assim, a serem prisioneiros dessas paixões - é necessário reconhecer o núcleo democrático na origem de muitas de suas demandas.

Sua visão destoa de algumas correntes atuais que repelem o uso do populismo para referir-se aos fenômenos políticos protagonizados na europa atualmente. Conforme Mouffe, classificar os partidos como de "extrema direita" ou "neofascistas" e atribuirlhes o grande apelo à falta de educação dos seus seguidores (ou seja, estabelecer uma fronteira moral) é, além de errado, conveniente para a centro-esquerda, pois lhes permite desqualificá-los sem ter que admitir sua própria responsabilidade por sua emergência. A estratégia de "demonização dos inimigos" pode ser moralmente confortante, mas é politicamente enfraquecedora.

Em sua visão, uma abordagem populista de esquerda deveria tentar prover um novo vocabulário, visando orientar estas demandas em direção a objetivos mais igualitários ${ }^{7}$. Trata-se de consolidar uma disputa hegemônica, ou seja, desarticular as práticas sedimentadas na formação existente e, através da transformação dessas e da instauração

7 A proposta de Chantal Mouffe tem proximidade com argumentos já apresentados por autores como Stavrakakis (2014). 
Por um populismo de esquerda.

MOUFFE, Chantal. For a Left Populism. London/Verso, 2018.

Revista Ensaios, vol. 15, jul-dez de 2019.

de novas práticas, estabelecer pontos nodais de uma nova formação hegemônica. Isso requer a rearticulação dos significantes hegemônicos e sua forma de institucionalização. Em outras palavras, deve-se disponibilizar uma linguagem diferente para que essas pessoas possam significar sua situação de um modo diferente e se juntem à disputa progressista.

Articular democracia com a igualdade de direitos, com a apropriação social dos meios de produção e com a soberania popular é, na visão de Mouffe, um caminho para comandar e atualizar diferentes práticas socioeconômicas. Ao propor uma articulação que se confronta a atual - que se dá com o livre mercado, com a propriedade privada e com o individualismo irrestrito - o que se vislumbra é a constituição de um novo bloco histórico de modo transversal, que possa estabelecer e aprofundar os valores constitutivos da política democrática de igualdade e soberania popular como protagonistas.

Mouffe alerta que na conjuntura atual a construção da dimensão populista não é suficiente, é necessário que se qualifique como populismo de esquerda, uma denominação que deve ser empunhada com clareza e tomada como princípio norteador. Essa apropriação faz-se necessária principalmente porque, como pondera, o caminho sugerido - recriar novas fronteiras políticas - têm o potencial ter o efeito contrário ao desejado e levar a regimes autoritários que enfraqueçam as instituições. Por isto a importância de se ter como fundamento desta articulação valores pluralistas e igualitários. 
Por um populismo de esquerda.

MOUFFE, Chantal. For a Left Populism. London/Verso, 2018.

Revista Ensaios, vol. 15, jul-dez de 2019.

Referências bibliográficas:

CROUCH, Colin. Post-Democracy. Cambridge, UK/Polity, 2004.

LACLAU, Ernesto. On Populist Reason. New York and London/Verso, 2005.

LACLAU, Ernesto and Mouffe, Chantal. Hegemony and Socialist Strategy: Towards

a Radical Democratic Politics. New York and London/Verso, 1985.

MOUFFE, Chantal. For a Left Populism. London/Verso, 2018.

MOUFFE, Chantal. On the Political. Abingdon, UK/ Routledge, 2005.

RANCIÈRE, Jacques. Disagreement: Politics and Philosophy, trans. Julie Rose. Minneapolis/ University of Minnesota Press, 1999.

STAVRAKAKIS, Yannis. The Return of "the People": Populism and Anti-Populism in the Shadow of the European Crisis. Constellations, 2014, 21(4), 505-517. 